\section{Treatment of Congestive Heart Failure}

To the Editor: In their Scientific Review article about treatment of advanced heart failure, Dr Nohria and colleagues ${ }^{1}$ do not discuss relief of dyspnea by administration of low-dose narcotics. $^{2}$

The literature in hospice and palliative care has numerous citations about the usefulness of narcotics for palliation of symptoms. ${ }^{2-4}$ I have found that some patients have dramatic relief of their symptoms and commonly ask why previous physicians did not offer this simple treatment with its dramatic results. Patient and family education about disease management along with successful advance planning allows patients with advanced heart failure to be treated effectively at home.

As a final note, since advanced heart disease is a fatal illness, I also encourage physicians to initiate discussions about advance care planning to ensure that patients receive care that is consistent with their wishes.

Richard D. Brumley, MD

Southern California Permanente Medical Group Downey

1. Nohria A, Lewis E, Stevenson LW. Medical management of advanced heart failure. JAMA. 2002;287:628-640.

2. Weissman D. Dyspnea at End-of-Life. Milwaukee: End-of-Life Physician Education Resource Center, Medical College of Wisconsin; November 2000.

Fast Facts and Concept No. 27. Available at: http/www.eperc.mcw.edu. Accessibility verified April 3

3. Galanos A. Long-term care in geriatrics. Clin Fam Pract. 2001;3:683-694.

4. Friesinger G, Butler J. Heart failure in the elderly, clinics in geriatric medicine. 2000:16:663-675.

To the Editor: In their Scientific Review article about the management of advanced heart failure, Dr Nohria and colleagues ${ }^{1}$ suggested that angiotensin II receptor blockers (ARBs) are a reasonable alternative for patients who cannot tolerate angiotensin converting enzyme (ACE) inhibitors because of severe cough or angioedema. Although we agree that ARBs, or a combination of hydralazine and a nitrate, constitute a reasonable alternative in patients experiencing persistent cough associated with receiving ACE inhibitors, we believe that ARBs in patients with a history of an ACE inhibitor-associated angioedema should only be used with extreme caution, if at all.

ACE inhibitor-associated angioedema can occur hours to years following drug initiation. ${ }^{2}$ The mechanism of ACE inhibitor-associated angioedema has not been completely elucidated. Some have suggested that this adverse drug reaction is secondary to the inhibition of bradykinin metabolism and accumulation, resulting from ACE inhibition, although other proposed mechanisms include release of histamine, substance $\mathrm{P}$, and prostaglandin. ${ }^{3,4}$ Black patients are at particular risk for developing angioedema. Although others have also recom- mended ARBs in patients previously experiencing ACE inhibitor-associated angioedema, ${ }^{1,5}$ recent data have questioned the safety of this practice. ${ }^{2,3}$ Moreover, an analysis of published cases indicated that in $32 \%$ of patients with ARB-associated angioedema had a history of ACE inhibitor-associated angioedema. ${ }^{2}$ Of even more concern is that in some cases, ARBs were not identified as the responsible agent; thus, continuation of the drug following the first episode resulted in further episodes of angioedema ${ }^{3}$

We believe that a combination of hydralazine and a nitrate represents a safer and more appropriate alternative for treatment of left ventricular dysfunction in patients with a history of ACE inhibitor induced angioedema.

Simon de Denus, MSc(Pharm)

Philadelphia College of Pharmacy

University of the Sciences in Philadelphia

Sarah A. Spinler, PharmD

Philadelphia College of Pharmacy

University of the Sciences in Philadelphia

Department of Medicine, Cardiovascular Section

University of Pennsylvania

Philadelphia

1. Nohria A, Lewis E, Stevenson LW. Medical management of advanced heart failure. JAMA. 2002;287:628-640.

2. Warner KK, Visconti JA, Tschampel MM. Angiotensin II receptor blockers in patients with ACE inhibitor-induced angioedema. Ann Pharmacother. 2000;34 526-528.

3. Chiu AG, Krowiak EJ, Deeb ZE. Angioedema associated with angiotensin II receptor antagonists: challenging our knowledge of angioedema and its etiology. Laryngoscope. 2001;111:1729-1731.

4. Vleeming W, van Amsterdam JGC, Stricker BHC, de Wildt DJ. ACE-inhibitor induced angioedema. Drug Safety. 1998;18:171-188.

5. Hunt SA, Baker DW, Chin MH, et al. ACC/AHA guidelines for the evaluation and management of chronic heart failure in the adult: executive summary: a report of the American College of Cardiology/American Heart Association Task Force on Practice Guidelines (Committee to revise the 1995 Guidelines for the Evaluation and Management of Heart Failure). J Am Coll Cardiol. 2001;38:2101-2113.

To the Editor: Dr Nohria and colleagues ${ }^{1}$ provide no evidence for their conclusion that heart failure hospitalization rates "are reliably decreased by experienced heart failure physiciannurse teams making decisions but not by centralized nursing services providing patient contact but no intervention except

GUIDELINES FOR LETTERS. Letters discussing a recent JAMA article should be received within 4 weeks of the article's publication and should not exceed 400 words of text and 5 references. Letters reporting original research should not exceed 500 words and 6 references. All letters should include a word count. Letters must not duplicate other material published or submitted for publication. Letters will be published at the discretion of the editors as space permits and are subject to editing and abridgment. A signed statement for authorship criteria and responsibility, financial disclosure, copyright transfer, and acknowledgment is required for publication. Letters not meeting these specifications are generally not considered. Letters will not be returned unless specifically requested. Also see Instructions for Authors (January 2, 2002). Letters may be submitted by surface mail: Letters Editor, JAMA, 515 N State St, Chicago, IL 60610; e-mail: JAMA-letters@ama -assn.org; or fax (please also send a hard copy via surface mail): (312) 464-5225.

Letters Section Editor: Stephen J. Lurie, MD, PhD, Senior Editor.

(Reprinted) JAMA, May 1, 2002-Vol 287, No. $17 \mathbf{2 2 0 9}$ 
through multiple primary providers." We believe that the metaanalysis $^{2}$ they cited in support of this conclusion is flawed. One ${ }^{3}$ of the 2 studies in the meta-analysis that was categorized as evaluating telephonic "centralized nursing services" to enhance primary care follow-up did not even focus on a heart failure disease management program. Instead, patients in the Veterans Affairs (VA) health care system with a variety of chronic illnesses received global primary care clinician and nursing support. Second, the patients in the VA study had higher comorbidity and lower baseline quality of life scores than patients in the other studies included in the meta-analysis. Third, the authors of the VA study acknowledged that many factors unique to the VA system may have influenced their findings and thus would limit their generalizability to other health care systems. The appropriateness of quantitatively combining data from this study with the others is questionable, regardless of the results of heterogeneity testing.

In contrast to the conclusions of Nohria et al, we recently reported on the results of a 1-year randomized trial ${ }^{4}$ of a videobased home telecare intervention in which we found that the mean charges for heart failure-related readmission were $86 \%$ lower for the telecare group and 84\% lower for the telephone group than the mean charges for the patients who received usual care. The large difference in readmission charges between the usual care and intervention groups did not reach statistical significance, probably due to the small sample size. However, both interventions resulted in significantly fewer congestive heart failure-emergency department visits and charges.

Although specialist expertise may sometimes be required for optimal management of heart failure, the majority of patients with heart failure are managed principally by primary care physicians. ${ }^{5}$ Generalists and specialists alike should strive to develop collaborative approaches to heart failure management.

Anthony F. Jerant, MD

Department of Family and Community Medicine University of California, Davis

1. Nohria A, Lewis $E$, Stevenson LW. Medical management of advanced heart failure. JAMA. 2002;287:628-640.

2. McAlister FA, Lawson FME, Teo KK, Armstrong PW. A systematic review of randomized trials of disease management programs in heart failure. Am J Med. 2001;110:378-384.

3. Weinberger $M$, Oddone EZ, Henderson WG. Does increased access to primary care reduce hospital readmissions? N Engl J Med. 1996;334:1441-1447.

4. Jerant AF, Azari R, Nesbitt TS. Reducing the cost of frequent hospital admissions for congestive heart failure: a randomized trial of a home telecare intervention. Med Care. 2001;39:1234-1245.

5. National Center for Health Statistics. National Ambulatory Medical Care Survey, 1989 Summary. Hyattsville, Md: US Dept of Health and Human Services; 1992. Vital Health Stat 13, No. 110

In Reply: We appreciate these perspectives. As Dr Brumley suggests, the increasing population of patients with truly endstage disease mandates more thoughtful approach to their suffering, which can certainly be alleviated by oral opiates. Drs de Denus and Spinler note that recent information regarding ACE inhibitors does raise considerable concern that these agents may not be indicated for patients with a history of angioedema from ACE inhibitors. Dr Jerant describes the success of his program for managing heart failure. The majority of patients with heart failure are indeed followed up in primary care practices. The clinicians in these settings have by far the most challenging responsibility to provide comprehensive ongoing care for heart failure while managing multiple other complex chronic illnesses.

Few practicing physicians now can set aside sufficient time for patient education and regular telephone calls to monitor daily fluctuations in clinical status. Whether the supervising physician is a heart failure specialist or primary care physician, a team approach is critical to optimize outcome for these patients. Dedication and experience is required for the nurse specialist to help patients establish an optimal medical regimen, particularly for the initiation and titration of $\beta$-blockers. Our emphasis was not on the credentials of nurse-physician teams, but rather on their familiarity with these patients and the flexibility to intervene rapidly to avert decompensation. These functions are limited for national call-in systems that are isolated from the direct providers.

Our article focused on patients with advanced heart failure in whom severe symptoms persist after the usual therapies have been attempted. Many of the newer therapies for these patients are available only in specialized heart failure centers, where this team approach evolved through heart transplantation and clinical trials. For the broader heart failure population, many different approaches have effectively reduced rehospitalization. ${ }^{1-3}$ These should be adapted to the patient populations, practice patterns, and available resources for each community. As the number of patients with heart failure continues to increase, more nurses trained in heart failure management will be needed to enhance primary care of heart failure in all communities.

Lynne Warner Stevenson, MD

Brigham and Women's Hospital

Boston, Mass

1. Jerant AF, Azari R, Nesbitt TS. Reducing the cost of frequent hospital admissions for congestive heart failure: a randomized trial of a home telecare intervention. Med Care. 2001;39:1234-1245.

2. Kasper EK, Gerstenblith G, Hefter G, et al. A randomized trial of the efficacy of multidisciplinary care in heart failure outpatients at high risk of hospital readmission. J Am Coll Cardiol. 2002;39:471-480.

3. Grady KL, Dracup K, Moser DK, Piano M, Stevenson LW, Young JB. Team management of patients with heart failure: a statement for healthcare professionals from the Cardiovascular Nursing Council of the American Heart Association. Circulation. 2000;102:2443-2456.

\section{Postmenopausal Hormone Replacement, Body Mass Index, and Quality of Life}

To the Editor: Dr Hlatky and colleagues ${ }^{1}$ reported that postmenopausal hormone therapy improved quality of life only among women who reported flushing at baseline. We suspect that the women in this study who reported flushing were generally thinner than those who did not; thus, we suggest that the results should be reported stratified by body mass index (BMI). Menopausal symptoms, including flushing, are related to the dramatic decrease of estrogen levels due to depletion of 
ovarian function. After menopause, peripheral aromatization of androgens in adipose tissue is the primary source of endogenous estrogen, and circulating levels of estrogen in postmenopausal women increase with increasing body mass. ${ }^{2}$ Significantly lower levels of estradiol and estrone are found in women with frequent hot flashes, ${ }^{2}$ and flushing is more likely among thin women. ${ }^{2}$

Several observational studies have suggested that both risks and benefits of hormone therapy are observed only in thin women. ${ }^{3,4}$ Breast cancer rates are generally lower among thin postmenopausal women and increase with hormone therapy, while there appears to be no such increase among women with higher BMI. ${ }^{3}$ Similarly, we have reported that the inverse association between hormone use and coronary heart disease was strongest for thin women. ${ }^{4}$ These results suggest that there may be a threshold level of estrogen beyond which additional exogenous estrogen has negligible effects.

Women included in the HERS trial, upon which Hlatky et al based their analysis, have higher BMI than average US women; $57 \%$ of the women in the treatment group 5 had a BMI of greater than $27 \mathrm{~kg} / \mathrm{m}^{2}$ compared with $43 \%$ of US women in the same age group. ${ }^{6}$ If there is indeed a threshold in the level of biologically important doses of estrogens, an improvement in mental health and depression associated with hormone use among women in the HERS trial would only be expected in thinner women.

Carmen Rodriguez, MD, MPH

Eugenia E. Calle, PhD

American Cancer Society

Atlanta, Ga

1. Hlatky MA, Boothroyd D, Vittinghoff $E$, Sharp $P$, Whooley MA. Quality-of-life and depressive symptoms in postmenopausal women after receiving hormone therapy: results from the Heart and Estrogen/Progestin Replacement Study (HERS) Trial. JAMA. 2002;287:591-597.

2. Erlik $Y$, Meldrum $D$, Judd $H$. Estrogen levels in postmenopausal women with hot flashes. Obstet Gynecol. 1982;59:403-407.

3. Collaborative Group on Hormonal Factors in Breast Cancer. Breast cancer and hormone replacement therapy: collaborative reanalysis of data from 51 epidemiological studies of 52,705 women with breast cancer and 108,411 women without breast cancer. Lancet. 1997;350:1047-1059.

4. Rodriguez C, Calle E, Patel A, Tatham L, Jacobs E, Thun M. Effect of body mass on the association between estrogen replacement therapy and mortality among elderly US women. Am J Epidemiol. 2001;153:145-152.

5. Hulley S, Grady D, Bush T, et al, for the Heart and Estrogen/progestin Replace ment Study (HERS) Research Group. Randomized trial of estrogen plus progestin for secondary prevention of coronary heart disease in postmenopausal women. JAMA. 1998;280:605-613.

6. Kuczmarski R, Carroll M, Flegal K, Troinano R. Varying body mass index cutoff points to describe overweight prevalence among US adults: NHANES III (1988 to 1994). Obesity Res. 1997;5:542-548.

In Reply: In response to Drs Rodriquez and Calle, only $28 \%$ of the women enrolled in HERS had a BMI of $25 \mathrm{~kg} / \mathrm{m}^{2}$ or less, and only $5 \%$ had a BMI of $20.9 \mathrm{~kg} / \mathrm{m}^{2}$ or less. We examined the quality-of-life measures in 3 strata of BMI: $25 \mathrm{~kg} / \mathrm{m}^{2}$ or less, more than 25 through $30 \mathrm{~kg} / \mathrm{m}^{2}$, and more than 30 $\mathrm{kg} / \mathrm{m}^{2}$. Overall quality of life scores declined significantly with increasing BMI. None of the tests for interaction between treatment assigned, follow-up time, and BMI were statistically significant, however, and there were no consistent trends between BMI and an effect of hormone therapy on quality of life.

Mark A. Hlatky, MD

Derek Boothroyd, PhD

Stanford University School of Medicine

Stanford, Calif

\section{Varicella Vaccine and Shingles}

To the Editor: Dr Seward and colleagues ${ }^{1}$ report that the incidence of varicella in the United States decreased following the introduction of vaccination. It is unclear, however, how varicella vaccination will affect the incidence of herpes zoster (HZ). It has been suggested that exposure to varicella can boost specific immunity to varicella zoster virus (VZV) and thus reduce the risk of reactivation. ${ }^{2}$ If this is the case, reduction of circulating VZV due to varicella vaccination would increase the overall incidence of $\mathrm{HZ}$; unvaccinated adults would be most at risk. This potential danger was recognized by the Food and Drug Administration at the time the varicella vaccine was licensed, ${ }^{3}$ and the Centers for Disease Control and Prevention (CDC) were recommended to conduct surveillance of both chickenpox and $\mathrm{HZ}$ cases after widespread use of the vaccine. ${ }^{4}$

Mathematical models have suggested that the greater the reduction in the incidence of varicella, the greater the ensuing increase in HZ. ${ }^{5}$ Thus, the dramatic decline in incidence observed by Seward et al might lead to a significantly increased incidence of $\mathrm{HZ}$ over the next 50 years. The incidence of $\mathrm{HZ}$ should eventually decline once the vaccinated cohorts reach old age because the varicella vaccine strain is less likely to reactivate than the wild type strain. ${ }^{5}$ Introduction of booster doses of varicella vaccine to prevent $\mathrm{HZ}$ may be an interim option. Thus, Seward et al report only half the story: trends in the annual age-specific incidence of $\mathrm{HZ}$ should be presented alongside the varicella data to show the full impact of the vaccination program on VZV disease.

Marc Brisson, MSc

W. John Edmunds, PhD

Nigel J. Gay, MSc

Elizabeth Miller, MBBS, MFPHM, FCRPath

Immunization Division

Public Health Laboratory Service Communicable Disease

Surveillance Center

London, England

1. Seward JF, Watson $B M$, Peterson $C L$, et al. Varicella disease after introduction of varicella vaccine in the United States, 1995-2000. JAMA. 2002;287:606-611. 2. Hope-Simpson RE. The nature of herpes zoster: a long-term study and a new hypothesis. Proc R Soc Med. 1965;58:9-12.

3. Food and Drug Administration. Summary for basis of approval. Available at: http://www.fda.gov/CBER/sba/varmer031795sba.pdf. Accessibility verified April 1, 2002.

4. Krause $P$, Klinman DM. Efficacy, immunogenicity, safety, and use of live attenuated chickenpox vaccine. J Pediatr. 1995;127:518-525.

5. Brisson M, Edmunds WJ, Gay NJ, et al. Modelling the impact of immunization on the epidemiology of varicella zoster virus. Epidemiol Infect. 2000;125:651659.

In Reply: We agree with Dr Brisson and colleagues that surveillance for $\mathrm{HZ}$ is essential for evaluating the impact of the 
varicella vaccination program. Because the population sizes in the varicella active surveillance sites are not sufficient to monitor age-specific HZ incidence, the CDC has funded 2 other sites-Massachusetts Department of Public Health and Group Health Cooperative (GHC) in Seattle-to conduct populationbased varicella and $\mathrm{HZ}$ surveillance and monitor age-specific incidence rates. Massachusetts has monitored incidence through a statewide telephone survey since $1998,{ }^{1}$ while GHC is examining its automated medical records since 1992. To date, no increase in $\mathrm{HZ}$ is evident in any age group in either site (CDC, unpublished data, 2001). ${ }^{2}$ However, continued surveillance is needed to detect any changes in $\mathrm{HZ}$ incidence.

A decline in VZV transmission resulting from widespread vaccination may affect persons with prior varicella, but is unlikely to affect vaccinated persons whose risk of $\mathrm{HZ}$ is much lower. ${ }^{3}$ The trigger for reactivation is poorly understood but appears to depend on a decline in cell-mediated immunity. Protection against reactivation may be the result of external boosting (contact with infectious cases), internal boosting (reactivation of the latent virus), or other factors. Brisson et $\mathrm{al}^{4}$ have modeled the changes in $\mathrm{HZ}$ epidemiology following vaccine introduction under different assumptions. Assuming that external boosting is the sole determinant of immunity, there could be an increase in $\mathrm{HZ}$ (range, $0 \%-30 \%$ ) over the next 5 to 40 years followed by a decrease as immunized individuals replace those infected with wild type VZV. Another theory suggests that VZV reactivates subclinically ${ }^{5}$ with resultant boosting of immunity ${ }^{6}$ with unknown effect on $\mathrm{HZ}$ incidence. Finally, if boosting does not affect the risk of $\mathrm{HZ}$, the disease will decline progressively as the population of vaccinated persons increases.

Given the morbidity of $\mathrm{HZ}$, an increase in incidence is of great concern. We are monitoring $\mathrm{HZ}$ incidence and will report more detailed findings as soon as they are available. In the meantime, we also await the results of a multicenter trial of a highertitre formulation of the Oka/Merck vaccine strain virus among persons older than 55 years that may prevent or modify $\mathrm{HZ}$ and provide the scientific basis to address vaccination for $\mathrm{HZ}$. Although we hope that varicella vaccination will result in declines in both varicella and $\mathrm{HZ}$ over time, protecting the large population of persons already at risk for $\mathrm{HZ}$ is a public health priority.

Jane F. Seward, MBBS, MPH

Aisha O. Jumaan, PhD, MPH

Karin Galil, MD, MPH

Melinda Wharton, MD, MPH

Centers for Disease Control and Prevention

Atlanta, Ga

1. Brooks D, Patnaik P, Yih WK, et al. Estimating the incidence of chickenpox and shingles in Massachusetts using the BRFSS. Paper presented at: 34th National Immunization Conference; July 2000; Washington, DC. Abstract 254.

2. Seward JF. Update on varicella and varicella vaccine, United States. Paper presented at: 41st Interscience Conference on Antimicrobial Agents and Chemotherapy; December 16-19, 2001; Chicago, III.

3. Hardy I, Gershon AA, Steinberg SP, LaRussa PL. The incidence of zoster afte immunization with live attenuated varicella vaccine: a study in children with leukemia. N Engl J Med. 1991;325:1545-1550.

2212 JAMA, May 1, 2002-Vol 287, No. 17 (Reprinted)
4. Brisson $M$, Edmunds WJ, Gay NJ, et al. Modelling the impact of immunization on the epidemiology of varicella zoster virus. Epidemiol Infect. 2000;125:651669.

5. Lungu O, Annunziato PW, Gershon A, et al. Reactivated and latent varicellazoster virus in human dorsal root ganglia. Proc Natl Acad Sci U S A. 1995;92: 10980-10984.

6. Krause PR, Klinman DM. Disseminated rashes and varicella vaccine. Pediatr Infect Dis J. 2001;20:467-468.

\section{RESEARCH LETTER}

\section{Chocolate Consumption and Platelet Function}

To the Editor: Flavonoid-rich foods and beverages have putative vascular health benefits, including protection against ischemic stroke and reductions in platelet reactivity. ${ }^{1-5}$ Tea, grapes, apples, and cocoa contain a class of flavonoids known as the flavanols, which includes epicatechin and catechin. Flavanols can polymerize, producing theaflavins and thearubigins (found in tea) and procyanidins (found in grapes, apples, and cocoa). We previously reported reductions in platelet primary hemostasis and glycoprotein IIb/IIIa expression 2 and 6 hours after subjects consumed $300 \mathrm{~mL}$ of cocoa containing a total of 897 mg of flavanols and procyanidins. ${ }^{3}$ We examined whether smaller amounts of chocolate could affect platelet function.

Methods. We measured platelet function in 18 adult subjects, without history of heart disease or other chronic disease, at baseline and at 2 and 6 hours after they consumed 25 g of semisweet chocolate chips (Mars Inc, Hackettstown, NJ), which contained $220 \mathrm{mg}$ of flavanols and procyanidins. Platelet function was assessed with the PFA-100 (Dade Behring, Deerfield, Ill), which measures platelet primary hemostasis as the time it takes for adenosine diphosphate (ADP)-stimulated or epinephrine-stimulated whole blood to occlude an aperture in a collagen membrane under high shear conditions. Congenital platelet defects, glycoprotein IIb/IIIa inhibition, and aspirin will prolong closure times with the epinephrine/collagen PFA-100 cartridge, while the ADP/collagen cartridge is insensitive to the effects of aspirin. Plasma epicatechin, the predominant flavanol found in chocolate, was measured by reversedphase high-performance liquid chromatography as a marker for flavanol absorption. Because platelet quiescence is maintained, in part, by nitric oxide and prostacylin produced from the intact endothelium, ${ }^{6}$ we also measured plasma concentrations of the prostacyclin metabolite 6-keto-prostaglandin- $\mathrm{F}_{1 \alpha}$, and the pro-inflammatory eicosanoids leukotriene (LT) $\mathrm{C}_{4}, \mathrm{D}_{4}$, $\mathrm{E}_{4}$. Closure times were compared with repeated-measures (RM) analysis of variance (ANOVA). Plasma metabolites were analyzed by ANOVA or by Kruskal-Wallis ANOVA, depending on whether the data were normally distributed. The Tukey allpairwise comparison test (which only indicates whether a $P$ value for a comparison is $<.05$ ) was performed if the $P$ value for the overall test was $<.05$.

Results. Relative to baseline, a significant increase in closure time was observed in both ADP/collagen-induced $(P=.006$; Friedman repeated measure analysis of variance [RM ANOVA],

C2002 American Medical Association. All rights reserved. 
Figure. Individual Changes in Platelet-Related Primary Hemostasis After Chocolate Consumption
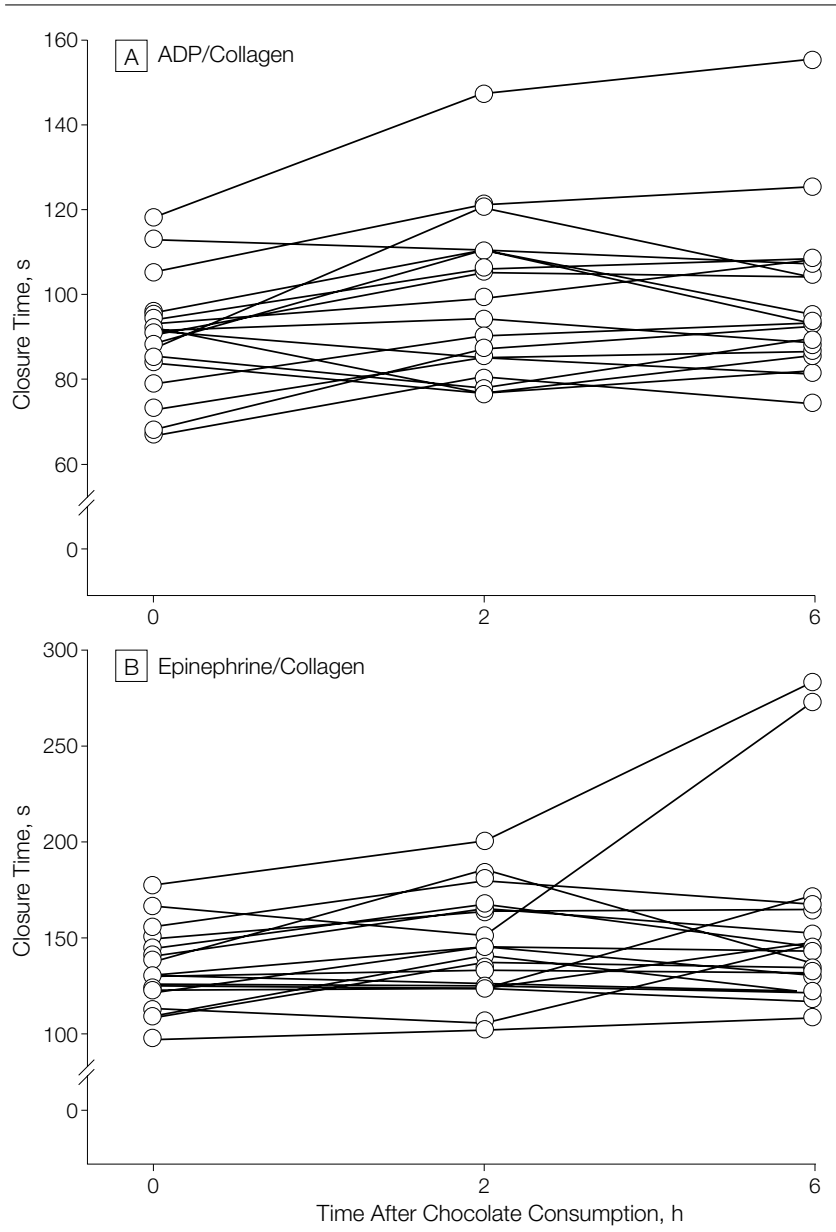

ADP indicates adenosine diphosphate

and Tukey all-pairwise comparison test; FIGURE, A) and epinephrine/collagen-induced $(P<.05$; RM ANOVA on ranks, and Tukey all-pairwise comparison test; Figure, B) primary hemostasis 2 hours after chocolate consumption. Six hours after consuming chocolate, the closure times were significantly increased with ADP/collagen $(P=.01$; Figure, A), but not epinephrine/collagen (Figure, B). We note that there were 2 outlying closure times in the epinephrine/collagen test at the 6-hour time point, although the cause is unknown.

Two hours after chocolate consumption we observed significant increases $(P<.05$; Kruskal-Wallis ANOVA on ranks,
Dunn all-pairwise comparison test) in mean (SD) plasma epicatechin concentrations (427 [249] nmoL/L) relative to baseline (39 [62] nmoL/L). This increase in plasma flavanol was transient in nature $(P<.05)$, with epicatechin concentrations decreasing to 114 (79) nmol/L by 6 hours. Plasma concentrations of 6-keto-prostaglandin- $F_{1 \alpha}$ were significantly increased at the 2 -hour $(P<.001)$ and 6 -hour $(P<.001)$ time points $(169.8$ [71.3] pg/mL and 163.1 [74.0] pg/mL, respectively) relative to baseline $(88.5[69.0] \mathrm{pg} / \mathrm{mL})$. In contrast, leukotriene concentrations were unchanged $(P=.995)$ from baseline 2 hours after chocolate consumption (163 [311] pg/mL and 39 [42] pg/mL, respectively). Overall, an antithrombotic eicosanoid response was observed at 2 hours, with the ratio of 6-keto-prostaglandin$\mathrm{F}_{1 \alpha}$ to LT $\mathrm{C}_{4}, \mathrm{D}_{4}$, and $\mathrm{E}_{4}$ significantly increased $(P<.05)$ over baseline (14 [35] and 23 [39], respectively).

Comment. We observed significant increases in plasma flavanol concentrations, with a concurrent increase in the ratio of prostacyclin to leukotriene shortly after consumption of a small amount of chocolate. We also observed reductions in both ADP/collagen-stimulated and epinephrine/collagenstimulated platelet-related primary hemostasis. These results support the concept that small amounts of foods rich in flavonoids, such as chocolate, can transiently affect platelet function.

Roberta R. Holt, BS

Derek D. Schramm, PhD

Carl L. Keen, PhD

Department of Nutrition

Department of Internal Medicine

University of California, Davis

Sheryl A. Lazarus, BS

Harold H. Schmitz, PhD

Analytical \& Applied Sciences

Mars Inc

Hackettstown, NJ

Funding/Support: This work is supported in part by grants from the National Institutes of Health (DK-35747) and Mars Inc.

1. Freedman JE, Parker Cl, LI L, et al. Select flavonoids and whole juice from purple grapes inhibit platelet function and enhance nitric oxide release. Circulation. 2001; 103:2792-2798.

2. Duffy SJ, Keaney JF Jr, Holbrook M, et al. Short- and long-term black tea consumption reverses endothelial dysfunction in patients with coronary artery disease. Circulation. 2001;104:151-156.

3. Rein $D$, Paglieroni TG, Wun $T$, et al. Cocoa inhibits platelet activation and function. Am J Clin Nutr. 2000;72:30-35.

4. Joshipura KJ, Ascherio A, Manson JE, et al. Fruit and vegetable intake in relation to risk of ischemic stroke. JAMA. 1999;282:1233-1239.

5. Kris-Etherton $\mathrm{P}$, Keen CL. Evidence that the antioxidant flavonoids in tea and cocoa are beneficial for cardiovascular health. Curr Opin Lipidol. 2002;13:41-49. 6. Vanhoutte P-M, Boulanger C-M, Mombouli J-V. Endothelium-derived relaxing factors and converting enzyme inhibition. Am J Cardiol. 1995;76:3E-12E. 